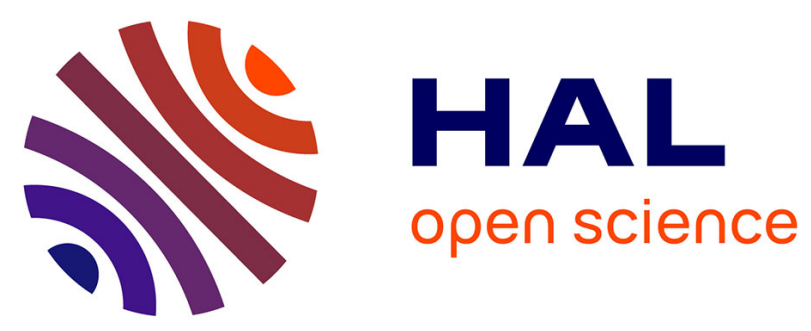

\title{
Urban Metabolism of Intermediate Cities: The Material Flow Analysis, Hinterlands and the Logistics-Hub Function of Rennes and Le Mans (France)
} Jean-Baptiste Bahers, Sabine Barles, Mathieu Durand

\section{- To cite this version:}

Jean-Baptiste Bahers, Sabine Barles, Mathieu Durand. Urban Metabolism of Intermediate Cities: The Material Flow Analysis, Hinterlands and the Logistics-Hub Function of Rennes and Le Mans (France). Journal of Industrial Ecology, 2018, 23 (3), pp.686-698. 10.1111/jiec.12778 . halshs-02195025

\section{HAL Id: halshs-02195025 \\ https://shs.hal.science/halshs-02195025}

Submitted on 26 Jul 2019

HAL is a multi-disciplinary open access archive for the deposit and dissemination of scientific research documents, whether they are published or not. The documents may come from teaching and research institutions in France or abroad, or from public or private research centers.
L'archive ouverte pluridisciplinaire HAL, est destinée au dépôt et à la diffusion de documents scientifiques de niveau recherche, publiés ou non, émanant des établissements d'enseignement et de recherche français ou étrangers, des laboratoires publics ou privés. 

the logistics-hub function of Rennes and Le Mans (France)

Jean-Baptiste Bahers, CNRS researcher, UMR ESO CNRS, Université de Nantes

Sabine Barles, professor at the Université Paris 1 Panthéon Sorbonne, Géographie-Cités UMR CNRS

Mathieu Durand, assistant professor at Université du Maine, UMR ESO CNRS

\begin{abstract}
:
Although urban metabolism has been the subject of renewed interest for some years, the related studies remain fragmented throughout the world. Most of them concern major cities (megacities and/or national capitals) and more rarely intermediate, medium-sized or small cities. However, urbanization trends show that together with the metropolisation process, another one is characterized by the proliferation of intermediate cities.

We have studied the metabolism of two French intermediate cities for the year 2012: Rennes Métropole, 400000 inhabitants, and Le Mans Métropole, 200000 inhabitants. To this end, we used material flow analysis (MFA) based on the methodology developed by Eurostat, adapted to the subnational level. This has been made possible by the use, for the first time, of very precise statistical sources concerning freight. We have developed a multiscale approach in order to weigh the urban metabolism of those two cities and to compare it to other cases and larger territories. This allows a better understanding of the specific territorial metabolism of intermediate cities, their hinterlands and their logistics-hub function. We conclude to the "urban dimension" of the social metabolism, and, thanks to the multiscale approach, to the debate regarding logistical hubs, dematerialisation and territorial autonomy.
\end{abstract}

Key words: urban metabolism, material flow analysis, cities, urbanization, hinterland, intermediate cities, spatialisation, logistics

\title{
<heading level 1> Introduction
}

Cities are key places for the implementation of sustainable development strategies. In her work, Cyria Emelianoff (Emelianoff 2007) relates how the sustainability concept in urban areas was first addressed to "stimulate local capacity to satisfy basic needs". The idea was to organise self-sufficient communities in terms of raw materials, especially food and energy. Recent research conducted from a territorial perspective adopted this view, in which a territory may constitute a resource against environmental, cultural and economic crises. In particular, it is argued that "sustainable" wealth can only be produced at the local level and based on an "environmental, social and cultural self-sustainability" (Magnaghi 2014). In this context, the "urban bioregion" (a concept derived from work by Patrick Geddes, 1915) allows material and energy flows to be integrated in a circular economy defined by its a geographic proximity. This questions the physical relationships which cities have with other territories, and the scope of their actual hinterland (Krausmann 2013; Bognon et al., forthcoming), compared to the ideal hinterland discussed in these debates (or projects of such a hinterland). To this respect, "How much of a 
city's resource demands can be met by local sourcing" (Voskamp et al. 2017) is a key issue and the spatialisation of urban metabolism, viewed as all energy and materials flows allowing a city to function, a way to address this issue. However, knowledge of urban metabolism is still incomplete. Although work in this field has been the subject of renewed interest for some years (Weisz and Steinberger 2010; Zhang et al. 2015), it remains fragmented throughout the world. Such research is limited to identifying direct flows whose geographical origin is often unknown, and when indirect flows are quantified, they are seldom spatialized, even though Zhang et al. (2015) cite some cases of quantification of indirect flows, and a special issue of Regional environmental change (Billen et al. 2012) was at one time devoted to the environmental footprint of cities and its location.

In addition, most of the research dedicated to urban metabolism is concentrated on metropolitan areas which are seen as the dominant form and paroxysm of global urbanisation. The enormity of the material and energy flows they bring into play are indeed worrying (see, for example, Kennedy et al. 2015). Yet, intermediate, medium-sized and small-sized cities contribute in significantly to the metabolism of human societies. Indeed, they are part of the contemporary urbanisation (and sometimes de- urbanisation) process. Analysing the energy and material flows they generate and on which they depend allows evaluating each city's specific impact on its local environment and on the areas supplying it or to which it releases its waste. Moreover, it shows the accumulated consequences of their individual activities. In France, the Greater Paris agglomeration, which has led to research on urban metabolism, certainly accounts for 10.6 million inhabitants. In comparison, small to medium size French cities accommodate collectively 41.6 million people, which is equivalent to $80 \%$ of the urban population and $63 \%$ of the overall French population (in 2013, INSEE). Their population is individually two to three orders of magnitude less than the Paris agglomeration, but they undeniably impact society's metabolism. At a global level, despite the diversity of urbanisation processes, intermediate, medium-sized or small cities play a role which is just as important.

For this reason, we have decided to study two medium-sized cities: Rennes (with a little more than 400,000 inhabitants, in the Brittany region) and Le Mans (a little less than 200,000 habitants, in the Pays de la Loire region). Both of these cities are located in western France. Apart from the intrinsic interest in knowing the metabolism of these agglomerations, these two new cases contribute to the new research aiming at defining the typology of territorial metabolism (Saldivar-Sali 2010; Barles 2014; Rosado et al. 2016). In addition, our analysis focuses on the spatialisation of urban metabolism, and some of its components are studied in detail as the import and exports flows (through the role of logistics), and the supply and disposal areas, at the departmental, regional, national and international scale. The second section presents the methodology used, based on the Eurostat methodology, as well as the data sources. Some of them are used for the first time at the communal level (freight). This methodology ends by identifying the main socio-economic and geographical characteristics of the two cities under study. The results of the metabolism analysis are then set out in the third section: material flow analysis, indicators for spatialisation, and supply and disposal areas for solid waste are compared for Le Mans and Rennes. The results are discussed in the fourth section, which allows metabolic characteristics of these medium-sized cities with a logistics-hub function to be identified, especially in comparison with studies conducted for other types of territory (megacities and rural areas).

\section{<heading level 1> Material \& Method}

The methodology used in this approach aims to quantify territorial metabolism at the city level. To this end, we use material flow analysis (MFA) based on adapting the methodology by Eurostat (2001 \& 2009) for sub-national levels (Barles 2009, 2010, 2014). This is the most-used and robust method. It allows the main input and output flows to be identified, so that the urban material imprint can be 
measured along with some of its consequences on the environment. This choice also has the advantage of prolonging studies carried out in France (Barles 2009, 2014; Bahers et al., 2016) and comparing them to other territories investigated by the scientific community.

\section{<heading level 2> Material Flow Analysis (MFA) and spatialisation}

Carrying out an MFA requires firstly quantifying inputs: local biomass, mineral and fossil fuel extraction, as well as imports of raw materials, semi-finished or finished products. Next, outputs need to be quantified: commercial exports (raw materials, semi-finished and finished products), waste exports, waste released locally into nature (atmospheric emissions, water emissions, landfilling, etc.), and lastly dissipative flows which associate dissipative uses (mineral fertilisers, farmyard manure, sewage sludge, solvents, thawing and grit materials, etc.), with dissipative losses being essentially due to wear and tear (abrasion of tyres, erosion of roads, etc.).

We have studied all the indicators used for comparing the two cities studied, as well as with other territories subsequently. Most of these indicators are common to the Eurostat methodology apart from three indicators added here: DMCp, DMC corr and LEPO (Barles 2009). Indeed, while DMC reflects apparent domestic consumption in a conventional manner (local extraction plus imports minus exports), DMCp shows physical consumption as it may be deducted from the conservation of mass principle, and by accounting for balancing flows. DMCcorr involves subtracting a share of DMC's imported waste and adding the share of exported waste: thus urban material consumption is not affected by imports or exports of waste. The LEPO indicator adds the exported processed outputs to nature with the local processed outputs to nature (DPO). Thus, when waste is treated out of the urban area, the resulting flows (emissions to air and water, landfilling, and dissipative use) are included in LEPO. LEPO makes it possible to measure total waste flows disposal into nature due to urban activities, and can be used as a basis for improving the spatial distribution of such outputs.

Our analysis gives an important place to the spatialisation of urban metabolism, and certain components are studied in detail here. These include:

- Import and export flows which are characterised by the major type of goods (manufactured products, agricultural and food products, construction materials, metal products, fertilisers and chemical products, fossil fuels, secondary raw materials, and other goods).

- Supply and emissions areas, at the departmental, regional, national and international scale.

- Waste flows which are analysed in order to identify the spatial levels of recycling, recovery and disposal (when waste is not treated locally). 


\section{<heading level 2> Heterogeneous sources of data}

The data used here combines statistical sources and local data. Data is given for 2012 as this was the most recent year for some sources. The statistics used are those of $\mathrm{BRGM}^{1}$ (for building material), AGRESTE $^{2}$ (for agricultural products), and SITRAM $^{3}$ (for the import and export flows of goods) ${ }^{4}$.

Until now, work conducted at the subnational level in France has been limited to regions and administrative departments, restricting urban MFAs to the Paris agglomeration (Paris being a French department $)^{5}$. This work also uses statistical sources at the communal level (notably for freight), which allows the method to be applied to the sub-departmental level, and hence permits analysis of cities other than Paris. Indeed, for the first time, it has been possible to use the SITRAM database at the communal level (this database is usually marketed by the French Ministry of Ecology at the departmental level). This has enabled MFAs to be undertaken for the two agglomerations selected in this research.

Although questions of waste and pollution emissions are on the political agenda, data showing their evolution is very unequal. The production of local data is gradually being regulated. Thus, a diagnosis of energy consumption and greenhouse gas emissions is now compulsory under France's Territorial Climate-Energy Plans (Plans Climat-Energie Territoriaux). Also, the territorial planning for managing all types of waste (apart from for agriculture) is regulated. However, the methodologies employed to carry out diagnoses of flows for these measures are not always similar and are poorly documented. Much depends on the willingness and capacity of local authorities to provide information, to specify the methodology used (especially concerning indirect flows) and hence to produce metadata. That said, we have been able to correct data and estimate these flows by checking their coherence with respect to the results provided by other regional statistics. For example, the consumption of fossil fuels in the EIDER database (Ministry of Ecology) compares data obtained from local institutions, as well as from data provided by regional waste monitoring organisations.

The heterogeneity of the data used, as well as its relative reliability and exhaustiveness require great care to be taken when using it. Unfortunately, it has not been possible to calculate uncertainty for all the data, given the lack of metadata in certain statistical databases. A qualitative analysis of the data's reliability was nevertheless conducted as part of the MUEED ${ }^{6}$ research project (Durand et al. 2016), to which the reader may refer.

${ }^{1}$ Bureau de Recherches Géologiques et Minières, a French public institution dedicated to mineral and hydrogeological resources.

${ }^{2}$ The statistical and evaluation database for agricultural forecasting by the French Ministry of Agriculture.

${ }^{3}$ The Système d'information sur les transports de marchandises database of the Ministry of Environment, comprising freight statistics.

${ }^{4}$ The Annex provides detailed information about the data sources.

${ }^{5}$ France is divided into 18 regions, each bringing together several departments (a total of 101 nationwide), which are themselves made up of several communes (a total of 35,416).

6“Urban Metabolism, Environmental Footprint and Waste Management" Project (Métabolisme Urbain, Empreinte Environnementale et gestion des Déchets), conducted by the Université du Maine (UMR ESO CNRS), 


\section{<heading level 2> Rennes and Le Mans: studying the metabolism of intermediate cities}

Le Mans and Rennes are two intermediate cities in the West of France (cf. Figure 1). In 2012, they respectively had populations of 184,446 and 414,149 inhabitants (INSEE, 2012). These figures relate to the political and administrative entities, known as the Urban Community of Metropolitan Le Mans (Communauté Urbaine de Le Mans Métropole) and the Agglomeration Community of the Rennes Metropole (Communauté d'Agglomération de Rennes Métropole) which brings together several communes. The Le Mans Metropole is concentrated in a tight space around the city centre, with a surface area of $157.41 \mathrm{~km}^{2}$ (INSEE, 2013). The territory is therefore very urbanised and only includes a few agricultural areas: land use for agriculture (Surface Agricole Utile or SAU) only accounts for $26 \%$ of the city's surface $\operatorname{area}^{7}$. In contrast, the Rennes Metropole is much more spread out. The agglomeration community is twice as populated as Le Mans and 4.5 times as big, with a surface area of $711.3 \mathrm{~km}^{2}$. It covers vast areas of agricultural land (SAU), which make up 45\% of the surface area (INSEE, 2013). The city is therefore able to produce far more raw materials (agricultural or minerals) than Le Mans.

The two cities are growing at slightly different rates, which may suggest different results in terms of metabolism. Rennes in fact experienced demographic growth of $1.2 \%$ between 2008 and 2013, while growth in Le Mans was only $0.2 \%$. This difference also stands out in the key sector for understanding of metabolism, namely construction: the number of housing units rose by 9.5\% between 2008 and 2013 in the Rennes Metropole, compared to only 3.4\% in the Le Mans Metropole. The number of jobs in the industrial sector is $9 \%$ in the Rennes Metropole and $12.1 \%$ in the Le Mans Metropole, which is much lower than the number of jobs in the trade, transport and services sector which corresponds to $51.7 \%$ in the Rennes Metropole and 49\% in the Le Mans Metropole. This partly explains the importance of the transit flows (imports and exports) and especially the crossing flows. Similarly, the share of companies classified in the productive sector ${ }^{8}$ by INSEE was $42.1 \%$ in Rennes, compared to $34.8 \%$ in Le Mans. This information is corroborated by the number of jobs and companies operating in agriculture and construction, which are more important in Rennes (in absolute and relative values) than in Le Mans.

Both cities are situated in the west of France, and are away from the major international transit flows crossing the country. However, Rennes is a natural land outlet for the Brittany region, and Le Mans an outlet for the whole of West France (the Brittany and Pays de la Loire regions). Both cities are, for example, road and rail gates to the Greater Paris region. The two cities are also well-connected to international goods trade via the proximity of major French ports (Saint Nazaire, Caen and even Le Havre). Their geographical position according to networks is a key factor for the flow circulation.

the École des Métiers de l'Environnement (UMR ESO CNRS) and the Université de Paris-Est Marne-La-Vallée (Lab’Urba - Génie Urbain), financed by ADEME from 2012 to 2016.

${ }^{7}$ The term city is henceforth used to indicate the Communauté Urbaine de Le Mans Métropole and the Communauté d'Agglomération de Rennes Métropole.

${ }^{8}$ According to INSEE, the productive sector corresponds to "activities which produce goods that are mainly consumed outside the zone". 


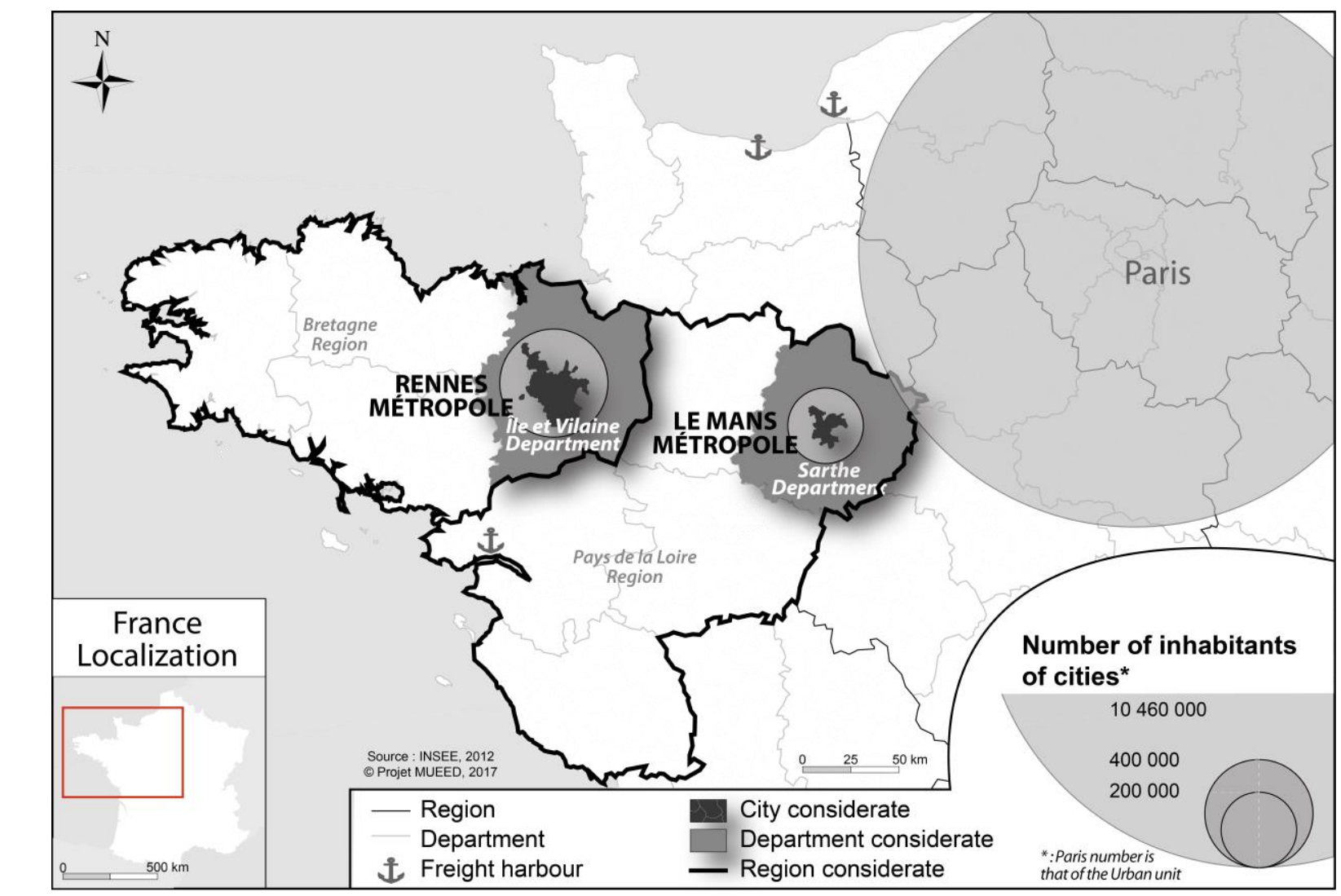

Figure 1. The location of Rennes and Le Mans (France)

<heading level 1> Results: the metabolism of Rennes and Le Mans

Figure 2 summarises the results obtained for the two cities. Although they indicate very different total flows, they have a similar magnitude relative to each city's population. Figure 3 also shows very similar profiles for the two cities, suggesting there is a metabolic homogeneity between them: each indicator (relative to the population) has a spread of less than $10 \%$ (less than $1.5 \mathrm{t} / \mathrm{cap}^{9}$ ) between the cities. We focus our analysis on indicators useful for understanding the spatialisation of flows: DMI and DMO.

9 “t” or "tons", as used throughout the article, refers to tonnes (metric tons). 

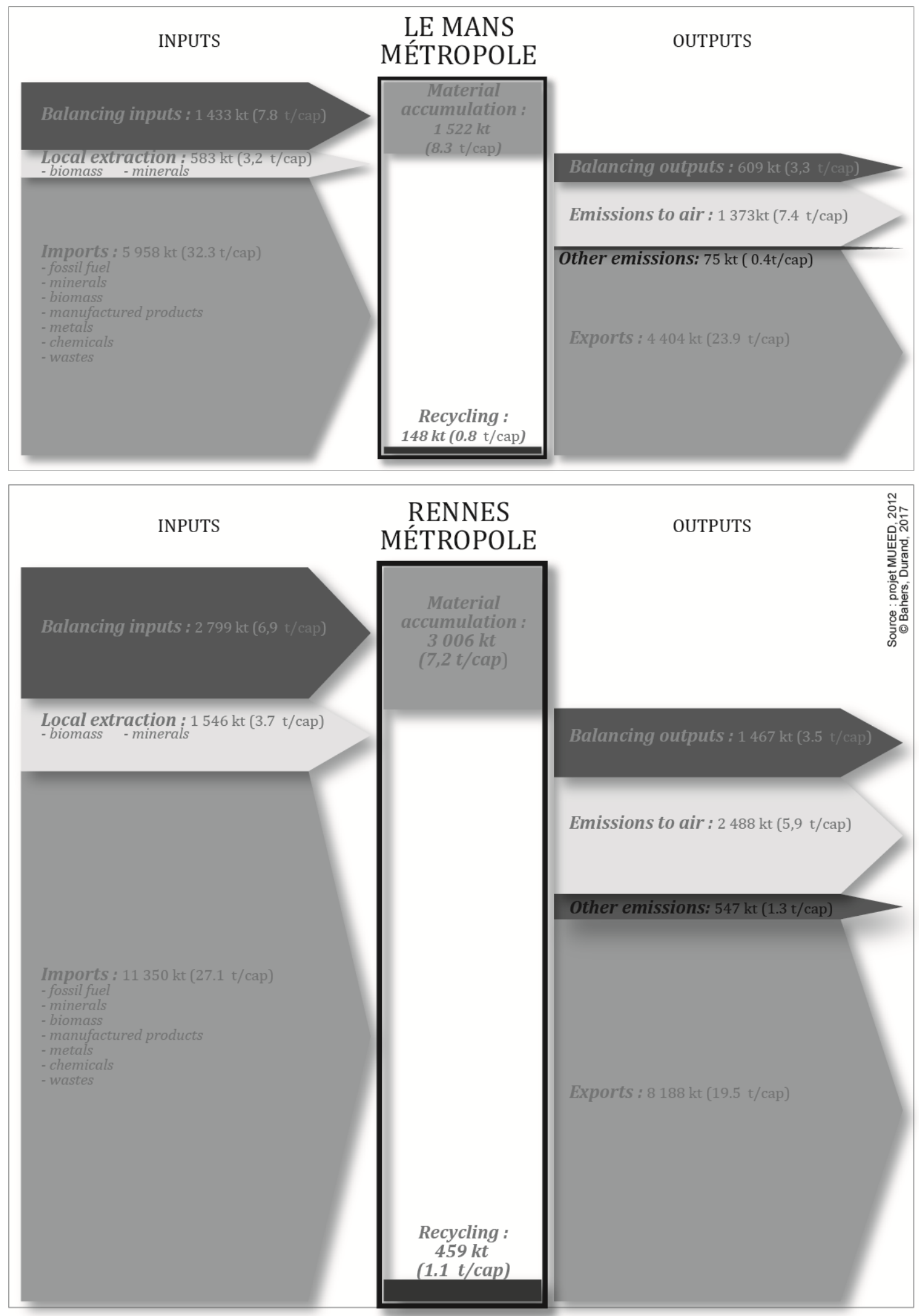

Figure 2. MFA for a) the Rennes Métropole and b) the Le Mans Métropole, kt/year (t/cap) (2012) 
In both cases, DMI is considerable: 30.7 t/cap in Rennes and 29.4 t/cap in Le Mans (cf. Figure Local extraction (construction materials and biomass) is minimal with respect to these imports (12\% of DMI in Rennes and 9\% in Le Mans), but accounts respectively for 32\% and 22\% of DMC, a difference that is partly due to land use in each city. These figures express the theoretical rate of gross material self-sufficiency for both cities; "theoretical" because there is nothing to suggest that local extraction is consumed locally, "gross" because materials are not distinguished. It is of course necessary to carry out a more detailed analysis to verify to what extent local extraction matches local needs. But this initial indicator provides a first impression of local possibilities, within the institutional perimeters (though these are not assumed to reflect a metabolic coherence and have not been defined as a function of selfsufficiency needs). The main imports are presented in Table 1 . They are dominated by non-metallic minerals (corresponding to construction materials) (38\% in Rennes and 25\% in Le Mans), biomass (19\% in Rennes and $31 \%$ in Le Mans), fossil fuels and manufactured products. Many of these imports are not consumed directly in the cities, as evidenced by exports. In addition, imported waste flows stood at 190 $\mathrm{kt}$ in Le Mans and $65 \mathrm{kt}$ in Rennes. This is a non-negligible amount of waste $(0.20 \mathrm{t} / \mathrm{cap}$ in Rennes and $1 \mathrm{t} / \mathrm{cap}$ Le Mans), as secondary raw materials used in industries.

Exports account respectively for $73 \%$ and $71 \%$ of DMO and are lower than imports: $7,7 \mathrm{kt}$ in Rennes and 8,4 kt in Le Mans. However, their composition is very similar to the one of imports (cf. Table 1). Some flows are actually "crossing flows", that is to say that they are not necessarily consumed or processed within the city, but only pass through the city (being only unloaded and loaded again) (Rosado et al. 2014; Voskamp et al. 2017). The exports are dominated by construction materials (35\% in Rennes and 28\% in Le Mans), biomass (18\% in Rennes and 30\% in Le Mans), fossil fuels and manufactured products. This highlights the importance of industrial and agricultural production in the transit flows. Processed outputs to nature reached 7.2 t/cap in Rennes and 7.9 t/cap in Le Mans, respectively $82 \%$ and $95 \%$ of emissions into the atmosphere (mainly carbon dioxide from vehicle motors). The difference can again be explained by the sustained level of agriculture in Rennes, which leads to dissipative uses and waste landfilling higher than in Le Mans. while disposal outside the urban perimeters due to the treatment of exported waste were $126 \mathrm{kt}$ in Le Mans and $274 \mathrm{kt}$ in Rennes. This is far from being negligible and affects DMCcorr (11.2 t/cap in Le Mans and $11.7 \mathrm{t} / \mathrm{cap}$ in Rennes) (cf. Figure 3).

Table 1. Imports and exports (the Rennes Metropole and the Le Mans Metropole, in 2012)

\begin{tabular}{|l|c|c|c|c|c|c|c|}
\hline \multirow{2}{*}{ Materials category } & \multicolumn{3}{|c|}{ Rennes Metropole } & \multicolumn{3}{c|}{ Le Mans Metropole } \\
\cline { 2 - 7 } & $\mathrm{kt}$ & $\mathrm{t} / \mathrm{cap}$ & $\%$ & $\mathrm{kt}$ & $\mathrm{t} / \mathrm{cap}$ & $\%$ \\
\hline $\begin{array}{l}\text { Manufactured } \\
\text { products }\end{array}$ & 2,192 & 5.29 & $19.32 \%$ & 1,079 & 5.85 & $18.11 \%$ \\
\hline Biomass & 2,161 & 5.22 & $19.04 \%$ & 1,849 & 10.02 & $31.03 \%$ \\
\hline Building minerals & 4,366 & 10.54 & $38.47 \%$ & 1,504 & 8.15 & $25.24 \%$ \\
\hline Metals & 180 & 0.44 & $1.59 \%$ & 113 & 0.61 & $1.89 \%$ \\
\hline Fossils fuels & 1,067 & 2.58 & $9.40 \%$ & 1,013 & 5.49 & $17.00 \%$ \\
\hline $\begin{array}{l}\text { Fertilizer and } \\
\text { chemical products }\end{array}$ & 129 & 0.31 & $1.14 \%$ & 57 & 0.31 & $0.96 \%$ \\
\hline Other products & 1,188 & 2.87 & $10.47 \%$ & 154 & 0.83 & $2.58 \%$ \\
\hline Imported waste & 65 & 0.16 & $0.57 \%$ & 190 & 1.03 & $3.19 \%$ \\
\hline
\end{tabular}




\begin{tabular}{|l|c|c|c|c|c|c|}
\hline Total Import & 11,350 & 27.40 & & 5,958 & 32.30 & \\
\hline \multicolumn{7}{|c|}{ Exports } \\
\hline $\begin{array}{l}\text { Manufactured } \\
\text { products }\end{array}$ & 1,588 & 3.83 & $19.39 \%$ & 663 & 3.60 & $15.06 \%$ \\
\hline Biomass & 1,520 & 3.67 & $18.57 \%$ & 1,335 & 7.24 & $30.32 \%$ \\
\hline Building minerals & 2,799 & 6.76 & $34.19 \%$ & 1,235 & 6.70 & $28.06 \%$ \\
\hline Metals & 139 & 0.33 & $1.69 \%$ & 81 & 0.44 & $1.83 \%$ \\
\hline Fossils fuels & 459 & 1.11 & $5.61 \%$ & 688 & 0.33 & $15.62 \%$ \\
\hline $\begin{array}{l}\text { Fertilizer and } \\
\text { chemical products }\end{array}$ & 91 & 0.22 & $1.11 \%$ & 60 & 1.17 & $1.36 \%$ \\
\hline Other products & 1,318 & 3.18 & $16.10 \%$ & 215 & 3.73 & $4.88 \%$ \\
\hline Exported waste & 274 & 0.66 & $3.35 \%$ & 126 & 0.68 & $2.86 \%$ \\
\hline Total Export & 8,188 & 19.77 & $100 \%$ & 4,404 & 23.88 & $100 \%$ \\
\hline
\end{tabular}

\section{<heading level 2> The spatialisation of the metabolism: a hinterland with a variable geometry}

The spatialisation of metabolism makes it possible to identify the origin of the various input flows and the destination of output flows. It provides numerous avenues of analysis about material relationships which cities have with their hinterlands for supply, distribution and waste. This multiscale approach to metabolism makes it possible to address issues relating to the socio-spatial and political aspects of resource management in urban areas (Bahers and Kim 2018), as other researchers do: "Making our analysis multiscale (rather than setting rigid system boundaries around the urban system) reveals an assemblage of local, metropolitan and global dynamics that shape cities' waste metabolisms"(Guibrunet et al. 2016).

Figure 3 presents the relative share of imports, exports, landfilling and recycling at different spatial levels (shown in Figure 2): urban, departmental, regional, national/international. It shows the very variable geometry of hinterlands according to the flows considered. Indeed, imports and exports are distributed unequally between the different levels. This translates a dependency of the cities studied with their outer environment. However, a majority of imports (around two thirds) comes from regional borders and certain types of goods clearly stem from more local supply areas. These include minerals, biomass and secondary materials. To be more precise, there are two main categories of goods (cf. Figure 4):

- the "local" goods. These goods are imported mainly at the departmental and regional level, such as biomass (68\% at Le Mans, 59\% at Rennes), construction minerals (90\% at Le Mans and $80 \%$ at Rennes) and secondary materials (90\% at Le Mans and Rennes).

- the highly globalized goods such as manufactured products (only 30\% of imports from the region for Le Mans and Rennes), fossil fuels (no local imports) and metals (7\% for Le Mans and 14\% for Rennes)

In addition, it is worth noting that exports follow the same logistics trajectories. Indeed, local goods are mainly exported within regional borders (between $60 \%$ and $80 \%$ in Le Mans and Rennes), which is not the case for more globalized goods (between $30 \%$ and $40 \%$ for the manufactured products 
and metals) (shown in Figure 4). Only fossil fuels do not obey this rule, as they are mostly exported within regional boundaries $(60 \%)$.

This reflects the relative solidarity which links cities to their territorial surroundings. This metabolic solidarity could be the basis for a materials policy designed at the interface of cities and regions, concerning in particular construction materials and biomass as mentioned previously. Such an inter-territorial approach is essential for implementing dematerialisation and loop-closing strategies, probably more than approaches that promote urban autonomy, which may be considered to contradict the very idea of the city (Barles 2015 \& forthcoming). However, such strategies are for the moment impeded by the economies of scale concerns by all actors, who favour industrial and infrastructural proximity and don't look for a social and spatial proximity (Bahers, Durand, 2017). As for public authorities, they presently do not have the legal and regulatory tools in France to bring supply hinterlands closer to cities.

Regarding processed outputs, the LEPO indicator is fundamental to showing that a share of emissions to nature is exported outside the urban zone: this is especially true for cities. If only landfill and emission to water are taken into account, then flows exported to nature $(0.7 \mathrm{t} / \mathrm{cap})$ are more significant in Le Mans than the total disposal into landfills and dissipative flows ( $0.4 \mathrm{t} / \mathrm{cap})$. Nearly twice as much solid and liquid waste is exported outside the city than is processed by urban infrastructures. The situation in Rennes is less contrasted, even if waste exports are very high. The city is therefore far from being autonomous in its processing capacity, leading to externalisation practices. Thus, in both Le Mans and Rennes, landfilling takes place either within the urban perimeter or in nearby territories, but also in more distant territories when processing activities require more advanced technology. Moreover, the majority of urban waste recycling is conducted nationally, or even worldwide: nearly $80 \%$ for Le Mans and more than $66 \%$ for Rennes, respectively $40 \%$ and $57 \%$ of which occurs outside France. The materials which are recovered thus experience the same kind of spatial trajectories which characterise secondary raw materials prices, implying massive exports towards very high consumption countries. If closing the material loop is a principle of the circular economy, its application at the worldwide level becomes meaningless in terms of urban metabolism. These results confirm what has been observed elsewhere: supply areas are greater than emission areas. However, they also show the importance of another geography concerning recycling, which seems to escape the principle of proximity. This is something public policies seem to omit. 


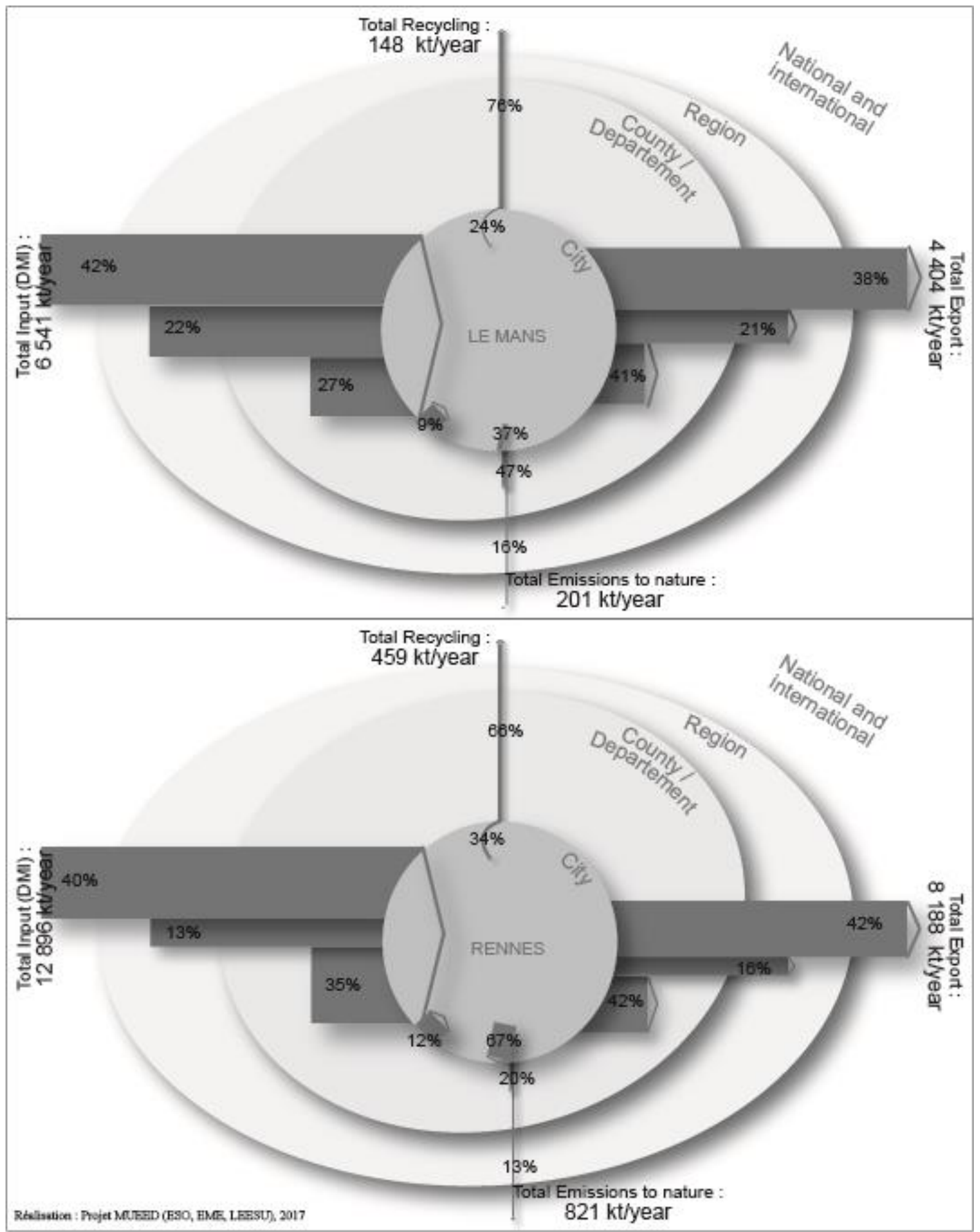

Figure 3. Shares of material relationships between cities and territorial levels in $\%$ and $\mathrm{kt} / \mathrm{year}$ 


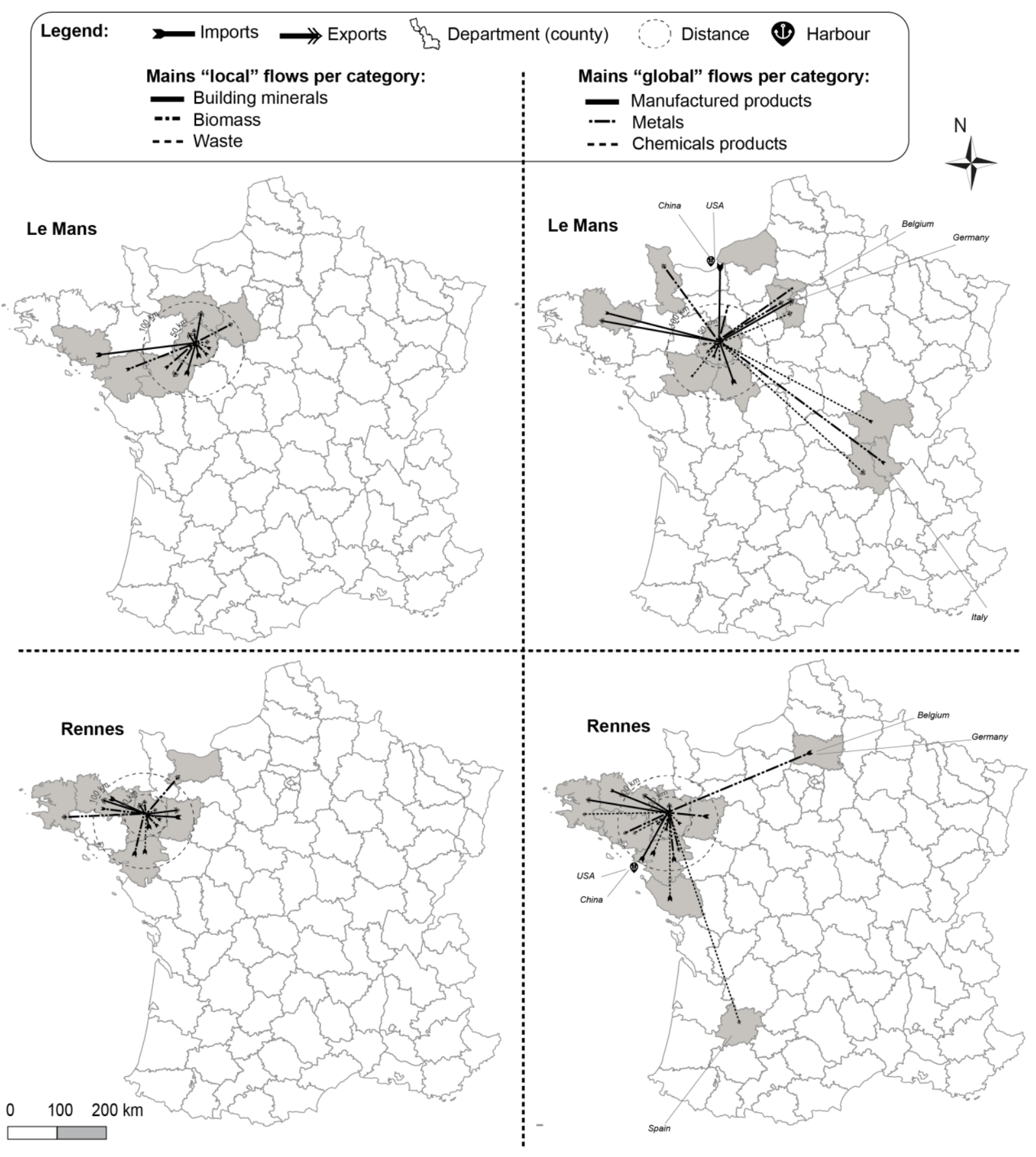

Figure 4. Spatialisation of local and global flows

<heading level 1> Discussion: what is the metabolic profile of intermediate cities with logisticshub function?

Rennes and Le Mans are two intermediate cities with comparable metabolisms, as we have seen. Figure 5 shows the contrasts which exist with other territories: a megacity (the Paris Metropolitan area (Paris and its dense suburbs) with 6,507,780 inhabitants and a surface area of $764 \mathrm{~km}^{2}$ ); a rural-industrial territory (Ariège, with 152,366 inhabitants and a surface area of 4,890 $\mathrm{km}^{2}$ ); and a mixed rural-urban area, such as the Department of Haute-Garonne (1,279,349 inhabitants and a surface area of $\left.6,309 \mathrm{~km}^{2}\right)$. The comparison shows a very clear difference between these territories: apart from DMI and DMO, all the indicators of the two intermediate cities here fall within those of the Paris Metropolitan area on the 
one hand and those of Ariège and Haute-Garonne on the other hand. The level of material consumption (11.2 t/cap and $11.7 \mathrm{t} / \mathrm{cap}$ for DMC and DMCcorr) is also quite similar to those of other European cities (Rosado et al. 2014; Sastre et al. 2015; Rosado et al. 2016; Athanassiadis et al. 2016), as well as the

4 French average (12 t/cap according to the $\left.\mathrm{CGDD}^{10}\right)$.

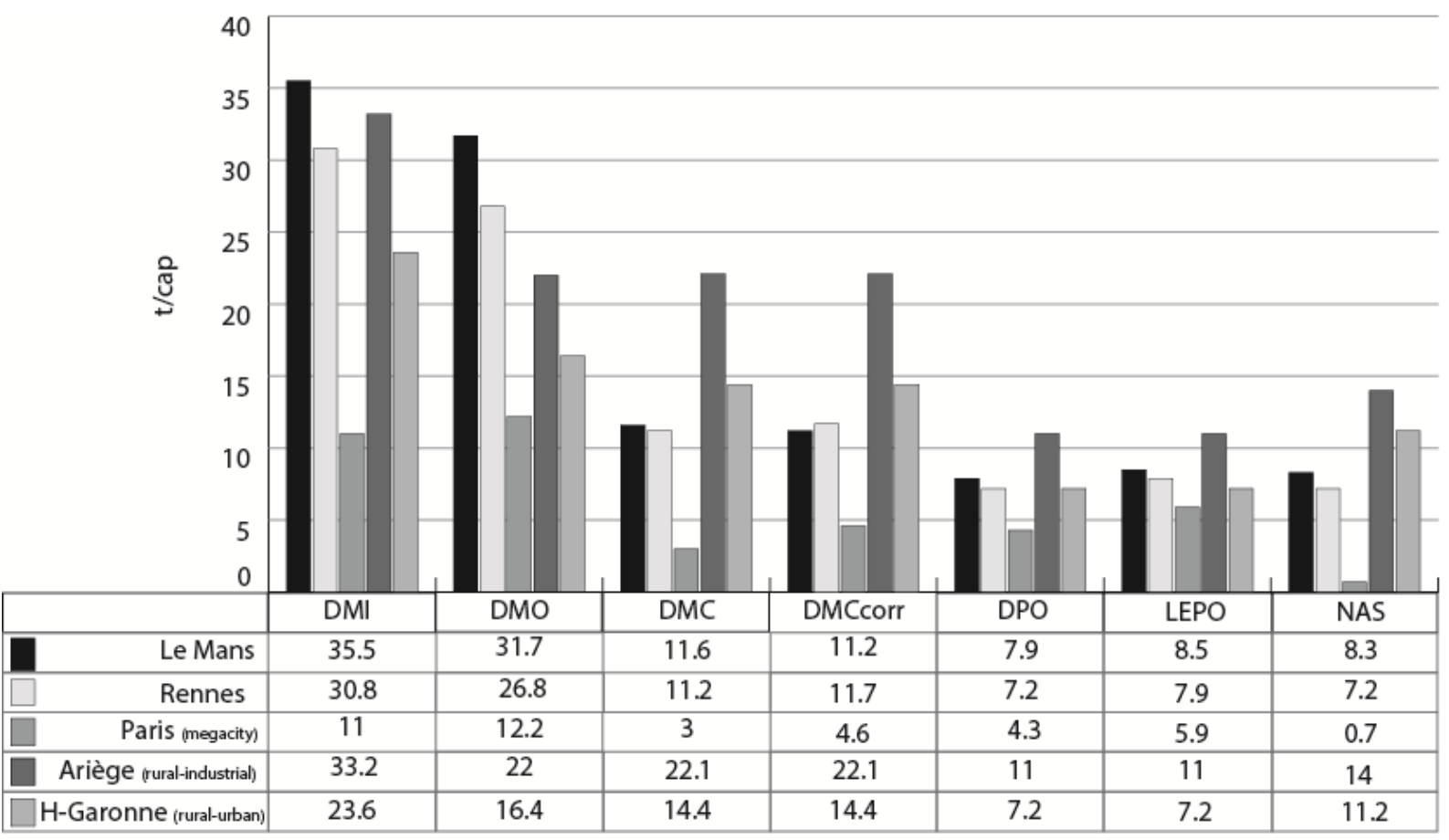

Figure 5. A comparison of the main MFA indicators in Le Mans and Rennes, with metropolitan Paris (central Paris and its dense suburbs) (Barles, 2009) and the departments of Ariège and Haute-Garonne (Barles, 2014)

The DMCp indicator, which represents the physical net domestic consumption of territories by including balancing flows in the accounting sheet, is far higher than the classical DMC, plus $39 \%$ in Le Mans and plus $28 \%$ in Rennes. These indicators are important because they contain the prospects for dematerialisation at city level. Opportunities for urban dematerialisation can be further explored by breaking down DMC into major material categories, shown in Figure 6, which again reflects quite a strong homogeneity between the two cities. The main materials in consumption are, not surprisingly, non-metallic minerals, i.e. construction materials, followed by biomass. In other words, meeting elementary needs of housing and food is still fundamental. It is also important to stress that the distribution of jobs and companies across industrial sectors, construction and agriculture are quite close in both towns, which justifies these similarities. Lastly, consumption of manufactured products and fossil fuels fluctuates between $1.5 \mathrm{t} / \mathrm{cap}$ and $2.3 \mathrm{t} / \mathrm{cap}$, whereas metal products are marginal. In terms of dematerialisation, this again reveals the issues already highlighted concerning urbanisation, to which

${ }^{10}$ Materials used by the French economy: a stabilised fall since the 2008 crisis CGDD, May 2016, available at:

$<$ http://www.statistiques.developpement-

durable.gouv.fr/fileadmin/documents/Produits_editoriaux/Publications/Chiffres_et_statistiques/2016/chiffres-

stats761-matieres-mai2016.pdf>, consulted the 15 June 2017. 
biomass should be added. Indeed, the bulk of biomass consumed in the cities is made up of food.

2 According to the INCA survey (Lafay, 2009), food consumption for adults aged 18 to 79 represents 3 nationally $1 \mathrm{t} / \mathrm{cap} /$ year (all manufactured food and drinks included). In contrast, the net consumption in 4 Rennes and Le Mans was more than $3 \mathrm{t} / \mathrm{cap}$, i.e. it had a differential of $2 \mathrm{t}$ due largely to losses and 5 wastage.
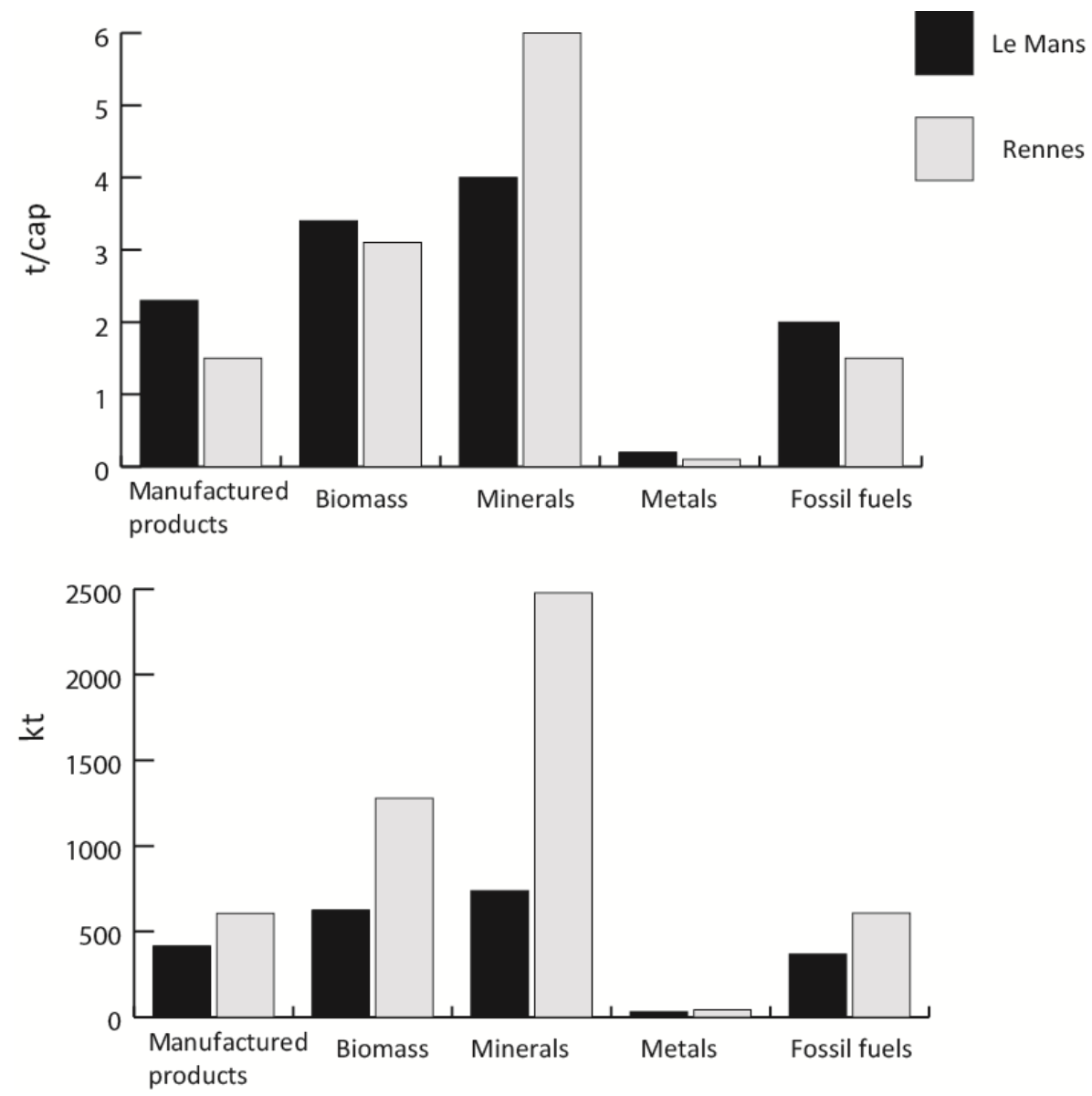

Figure 6. DMC by materials category in Rennes and in Le Mans, 2012, in t/cap and kt/year

By contrast, DMI and DMO are greater for both Le Mans and Rennes (cf. Figure 5). Transit flows (imports and exports) seems greater in intermediate cities than in other territories. This urban function is much more important than in a megacity, which is saturated by tertiary, decisional and residential functions, as well as in semi-rural territories whose infrastructure does not allow a substantial circulation of materials. However, it should be noted that few megacities also have important logistical roles, including those that are also harbors or strategically located. For example, DMI and DMO are also important for Barcelona, Amsterdam or Gothenburg (Rosado et al. 2014; Sastre et al. 2015; Voskamp et al. 2017), especially as cross-flows are excluded from imports and exports in these works. The role of big harbors serves as gateways for international and national trade (Rosado et al. 2014). As Ariège is a rural territory, it seems likely that it would require similar material imports (DMI); in fact these are substituted by the extraction of local minerals. Therefore, the imports and exports of Le Mans and Rennes are at least twice as important as those in other territories. These intermediate cities also collect materials which are then distributed to nearby territories. These are therefore logistical metabolisms mainly dedicated to the exchange of materials. Such a "centrifugal" metabolism is partly explained by the presence of hub and distribution activities in these urban areas. This result was also observed by a 
study of urban metabolism in Cape Town (South Africa), which manifests "the role of the city as a regional hub" (Hoekman and von Blottnitz 2016).

However, territories supplying materials and absorbing waste are not very far from these cities, at least in part (see $\S 3.3$ ) and translate specific socio-material relationships. This perspective runs counter to the theory of the planetary urbanisation put forward by Neil Brenner (Brenner 2013), and drawing on the work of Henri Lefebvre. It stipulates that all resources are controlled by urban actors. The relations between the cities and their hinterland are properly more complex and could be enriched by looking at metabolism from a political economy perspective (Demaria and Schindler 2016) which studies the spatialisation of power conflicts, sometimes driving new material and energy circulations.

Furthermore, the importance of imports and exports characterising the two cities leads to very important indirect flows. According to the CGDD (2016), and at the national level, these indirect flows represent on average $3.5 \mathrm{t}$ of hidden flows for every tonne of imported flows, and $4.1 \mathrm{t}$ for exports. Thus, for Le Mans and Rennes, the indirect flows associated with imports are respectively $110 \mathrm{t} / \mathrm{cap}$ and 76 $\mathrm{t} / \mathrm{cap}$, together with $62 \mathrm{t} / \mathrm{cap}$ and $42 \mathrm{t} / \mathrm{cap}$ for indirect flows associated with exports. This is considerable. For the country as a whole, these flows are far less important: about $30 \%$ according to Raupova et al. (2014). This is because imports and exports account for much less in the overall balance, in favour of national levels of extraction, consumption and waste disposed in nature. This externalisation of metabolism is an inherent characteristic of cities in general, but seems to be exacerbated in the case of intermediate cities which are logistical hubs.

Lastly, Le Mans and Rennes are characterised by strong additions to stocks and by significant waste disposal. In comparison, recycling is very low (only $1.1 \mathrm{t} / \mathrm{cap}$ in Rennes and $0.7 \mathrm{t} / \mathrm{cap}$ in Le Mans), which is of the same order of magnitude as in Ariège (1.7 t/cap), in Haute-Garonne (1.3 t/cap) or in Paris (0.7 t/cap) (cf. Figure 5). Recycling does not therefore participate much in urban dematerialisation, despite the numerous efforts made by inhabitants to sort their waste better. These practices are moreover largely supported by public policies which concentrate on this issue, suggesting that an "articulation of governmentality, then, instrumentalises a particular public in relation to waste" (Hird 2017, p4). These policies sometimes produce a rebound effect sustaining consumption when campaigns are undertaken to sensitise citizens to waste sorting. Indeed the production of household waste is significant $(0.46 \mathrm{t} / \mathrm{cap}$ in Rennes and 0.52 t/cap Le Mans), but remains less than construction/demolition waste (1.3 t/cap in Rennes and $0.68 \mathrm{t} /$ cap in Le Mans), and less than ordinary or dangerous waste from industry ( $0.53 \mathrm{t} / \mathrm{cap}$ in Rennes and $0.71 \mathrm{t} / \mathrm{cap}$ in Le Mans) and agricultural waste in Rennes $(0.80 \mathrm{t} / \mathrm{cap}$, and only $0.18 \mathrm{t} / \mathrm{cap}$ in Le Mans). Household waste therefore only represents $15 \%$ of total waste produced in Rennes and $25 \%$ in Le Mans. The NAS is far higher than in Paris, which seems to corroborate the importance of urbanisation mechanisms and urban sprawl, both in housing and infrastructures. The creation of artificial land (i.e. constructed land) is still going on in these cities (between 2006 and 2012, it concerned 631 ha in Rennes (+4.4\%), and 157 ha in Le Mans $(+1.8 \%)$ ). By contrast, Paris is characterised more by urban renewal rather than increases in material stocks. Urban sprawl can be clearly observed in intermediate cities, which is corroborated by the NAS/ha indicator which has values that are between 200 and 300 times greater than found in Ariège, Haute-Garonne and Paris.

\section{<heading level 1> Conclusion}


Intermediate cities are therefore characterised by a specific territorial metabolism which is clearly distinct from that of megacities or more rural zones. Their metabolism is in an intermediate position concerning the consumption of materials and local extraction per capita. These cities are situated between rural territories (with high levels of consumption linked to exports, and megacities (with low consumption per inhabitant). By contrast, intermediate cities have a strong logistics function, as most of the flows identified only transit through them as hubs, from more rural areas towards megacities. As a result, their metabolism is strongly externalised, with socio-material relations that are very open to their hinterlands. The identification of these zones of influence (areas of supply, distribution or emission) makes it possible to find several levels, including the local and regional levels that are essential to understanding the flow of materials. Intermediate cities therefore have a very strong metabolic relationship with their nearby rural environment, which constitutes a transit zone to territories further away. At the same time, their surrounding areas are the main destination of disposed waste and pollution emanating from the intermediate city. However, it remains to compare these intermediate cities to megacities that are also harbors, because their logistical roles are also very important.

Analysing the metabolism of medium-sized city thus highlights the characteristics of the consumer societies of the North, which are both dependent on large-scale flows, while still being linked to their nearby surroundings. If the circularity of flows and territorial autonomy are concepts which are becoming more significant in public discourse, their implementation seems to follow a variable geometry, depending on the materials, actors and territories in question.

\section{Bibliography}

Athanassiadis, A., P. Bouillard, R.H. Crawford, and A.Z. Khan. 2016. Towards a Dynamic Approach to Urban Metabolism: Tracing the Temporal Evolution of Brussels' Urban Metabolism from 1970 to 2010. Journal of Industrial Ecology: n/a-n/a.

Bahers, J.-B. and J. Kim. 2018. Regional approach of waste electrical and electronic equipment (WEEE) management in France. Resources, Conservation and Recycling 129(Supplement C): 45-55.

Barles, S. 2009. Urban metabolism of Paris and its region. Journal of Industrial Ecology 13(6): 898913.

Barles, S. 2010. Society, energy and materials: the contribution of urban metabolism studies to sustainable urban development issues. Journal of Environmental Planning and Management 53(4): 439-455.

Barles, S. 2014. L'écologie territoriale et les enjeux de la dématérialisation des sociétés : l'apport de l'analyse des flux de matières. Développement durable et territoires. Économie, géographie, politique, droit, sociologie(Vol. 5, $\left.\mathrm{n}^{\circ} 1\right)$. http://developpementdurable.revues.org/10090. Accessed January 3, 2017.

Barles, S. 2015. The main characteristics of urban socio-ecological trajectories: Paris (France) from the 18th to the 20th century. Ecological Economics 118: 177-185.

Billen, G., J. Garnier, and S. Barles. 2012. History of the urban environmental imprint: introduction to a multidisciplinary approach to the long-term relationships between Western cities and their hinterland. Regional Environmental Change 12(2): 249-253.

Brenner, N. 2013. Theses on Urbanization. Public Culture 25(1 69): 85-114.

Demaria, F. and S. Schindler. 2016. Contesting Urban Metabolism: Struggles Over Waste-to-Energy in Delhi, India. Antipode 48(2): 293-313.

Durand, M., J.-B. Bahers, and H. Beraud. 2016. Vers une économie circulaire... de proximité ? Une spatialité à géométrie variable. Déchets, Sciences et Techniques $\left(\mathrm{N}^{\circ} 71\right)$. 
http://lodel.irevues.inist.fr/dechets-sciences-techniques/index.php?id=3384. Accessed January 3, 2017.

Emelianoff, C. 2007. La ville durable : l'hypothèse d'un tournant urbanistique en Europe. L'Information géographique 71(3): 48.

Guibrunet, L., M. Sanzana Calvet, and V. Castán Broto. 2016. Flows, system boundaries and the politics of urban metabolism: Waste management in Mexico City and Santiago de Chile. Geoforum. http://www.sciencedirect.com/science/article/pii/S0016718516300380. Accessed June 16, 2017.

Hird, M.J. 2017. Waste, Environmental Politics and Dis/Engaged Publics. Theory, Culture \& Society 34(2-3): 187-209.

Hoekman, P. and H. von Blottnitz. 2016. Cape Town's Metabolism: Insights from a Material Flow Analysis. Journal of Industrial Ecology: n/a-n/a.

Kennedy, C.A., I. Stewart, A. Facchini, I. Cersosimo, R. Mele, B. Chen, M. Uda, et al. 2015. Energy and material flows of megacities. Proceedings of the National Academy of Sciences 112(19): 5985-5990.

Krausmann, F. 2013. A City and Its Hinterland: Vienna's Energy Metabolism 1800-2006. In Long Term Socio-Ecological Research, 247-268. Human-Environment Interactions. Springer, Dordrecht. https://link.springer.com/chapter/10.1007/978-94-007-1177-8_11. Accessed September 5, 2017.

Magnaghi, A. 2014. La biorégion urbaine. Paris: Editions Etérotopia, April 23.

Raupova, O., H. Kamahara, and N. Goto. 2014. Assessment of physical economy through economywide material flow analysis in developing Uzbekistan. Resources, Conservation and Recycling 89: 76-85.

Rosado, L., Y. Kalmykova, and J. Patrício. 2016. Urban metabolism profiles. An empirical analysis of the material flow characteristics of three metropolitan areas in Sweden. Journal of Cleaner Production 126: 206-217.

Rosado, L., S. Niza, and P. Ferrão. 2014. A Material Flow Accounting Case Study of the Lisbon Metropolitan Area using the Urban Metabolism Analyst Model. Journal of Industrial Ecology 18(1): 84-101.

Saldivar-Sali, A.N.D. 2010. A global typology of cities : classification tree analysis of urban resource consumption. Thesis, Massachusetts Institute of Technology. http://dspace.mit.edu/handle/1721.1/61558. Accessed September 5, 2017.

Sastre, S., Ó. Carpintero, and P.L. Lomas. 2015. Regional Material Flow Accounting and Environmental Pressures: The Spanish Case. Environmental Science \& Technology 49(4): 2262-2269.

Voskamp, I.M., S. Stremke, M. Spiller, D. Perrotti, J.P. van der Hoek, and H.H.M. Rijnaarts. 2017. Enhanced Performance of the Eurostat Method for Comprehensive Assessment of Urban Metabolism: A Material Flow Analysis of Amsterdam. Journal of Industrial Ecology 21(4): 887-902.

Weisz, H. and J.K. Steinberger. 2010. Reducing energy and material flows in cities. Current Opinion in Environmental Sustainability 2(3): 185-192.

Zhang, Y., Z. Yang, and X. Yu. 2015. Urban Metabolism: A Review of Current Knowledge and Directions for Future Study. Environmental Science \& Technology 49(19): 11247-11263. 